\title{
An outbreak of illness after occupational exposure to ozone and acid chlorides
}

\author{
T P NG, T W TSIN, AND F J O'KELLY \\ From the Occupational Health Division of the Labour Department, Hong Kong
}

\begin{abstract}
New labelling processes installed without adequate ventilation control in an electric motor factory exposed production line workers to toxic gases. Symptoms of eye and respiratory tract irritation together with complaints of headache, fever, chills, dizziness, malaise, general weakness, nausea, and vomiting were widespread. Chest signs, radiographic abnormalities, reduction in ventilatory function, and blood gas abnormalities were found in some cases. Epidemiological analysis of the spatial and temporal distribution of cases supported an exposure effect relationship. Investigations suggested ozone and possibly phosgene and associated trichloroacetyl chlorides as the toxic agents that were generated by an ultraviolet print curing arrangement and perchloroethylene used as a cleaning solvent.
\end{abstract}

Outbreaks of acute illness arising from toxic chemical contamination of the working environment affecting a large number of people are not common. We describe an incident where exposure to ozone and possibly phosgene and associated acetyl chlorides in a factory produced a mass gassing effect.

\section{Background}

The factory was engaged in manufacturing small electric motors for domestic appliances and toys and employed 240 women and six men on the fifth and sixth floors of a multistorey building. The floors (area 700 and $790 \mathrm{~m}^{2}$ ) were each ventilated by large air conditioning units and were arranged for open plan assembly line production. Processes included assembling, soldering, testing, labelling, and packaging various types of small motors. Working conditions were regarded as satisfactory and there were no general complaints until the introduction of a new labelling system.

The new process consisted of a cleaning pad moistened with perchloroethylene, an arrangement of inking and printing rollers using an epoxy resin based ink, and a curing section housing an ultraviolet light source. The motor casing was automatically cleaned, labelled, and dried as it moved along the production line. Although designed for the fitting of exhaust

Received 17 September 1984 Accepted 28 January 1985 ducting to the housing, this was not done at installation.

\section{Diary of events}

The new equipment was fitted on one of the prod uction lines on each floor and brought into use on Monday (day 1). An unpleasant smell described as "like rotten tomatoes" was noted, and a few workers complained of feeling unwell. On day 2 a second system started operation on the fifth floor to be followed two days later (day 4) by a second system on the sixth floor. There were some complaints of smell and irritation of eyes and throat. Production was closed down over the weekend from mid-day Saturday (days 6 and 7) and started again on Monday (day 8) with the addition of a third new system on the sixth floor. With five processes in operation at the beginning of the second week complaints of unpleasant smell and discomfort increased. On Tuesday (day 9) one worker was admitted to hospital in a serious condition and others began to seek medical attention. On day 10 operation of the new processes was suspended. Complaints of illness continued for several days and in the week up to Saturday (day 13) 191 of 246 who had been exposed attended the casualty department of a local hospital and 125 required admission.

\section{Investigation of circumstances}

All the workers were interviewed using a structured questionnaire to record personal identification, age, 
Table 1 Symptoms

\begin{tabular}{lcc}
\hline Symptoms & $\begin{array}{l}\text { No } \\
\text { affected }\end{array}$ & $\begin{array}{l}\text { \% of total } \\
(246)\end{array}$ \\
\hline Mucous membrane irritation: & 180 & 73 \\
$\quad$ Nose and/or throat irritation & 98 & 40 \\
Eye irritation & & \\
Respiratory system: & 205 & 83 \\
Cough & 132 & 54 \\
Productive cough & 73 & 29 \\
Dry cough & 136 & 55 \\
Chest pain and discomfort & 162 & 66 \\
Difficulty in breathing & 7 & 3 \\
Haemoptysis & 131 & 53 \\
Constitutional: & 104 & 42 \\
Fever & 108 & 44 \\
Chills & 112 & 45 \\
Headache & 105 & 43 \\
Dizziness & 59 & 24 \\
General malaise & 56 & 23 \\
Bodyache & & \\
Nausea/vomiting & & \\
\hline
\end{tabular}

sex, job description, working floor, seating position, and presence of specific symptoms including onset and duration and sickness absence during the period. Casualty attendance and hospital admission records were compared with questionnaire details, and clinical and laboratory findings were added to complete the record of the health experience and physical findings. The factory's attendance records were used to confirm the sickness absence details obtained at interview.

\section{Reported symptoms}

Of the 246 exposed subjects, $228(93 \%)$ complained of some ill effect (table 1). Cough, experienced by 205 , nose and throat irritation by 180 , and difficulty in breathing by 162 subjects were the most frequent symptoms. The difficulty in breathing was generally described as a sensation of "tightness" in the chest associated with shortness of breath. Chest pain and discomfort occurred in 136 whereas chills, headache, dizziness and general malaise were all somewhat less common. Some 56 complained of nausea whereas the least frequent symptom was haemoptysis reported by seven.

\section{Clinical findings}

The requirement for clinical tests was determined by the examining physician in relation to each patient's symptoms and physical condition. Table 2 shows the tests performed and the clinical findings as recorded for the 191 people who attended the casualty department including 125 admissions.

Fever was confirmed in 82,27 had lung signs, and 24 abnormal chest $x$ ray shadows. The lung findings were mostly crepitations equally frequent in one or both sides and localised over the bases in about half the cases. Eight of the abnormal chest $x$ ray findings showed single or multiple opacities of varying extent in one or both lungs whereas another 16 cases had increased lung markings with profuse mottled opacities or ill defined infiltrative opacities suggestive of pneumonitis.

Blood gas estimation showed reduced arterial $\mathrm{PO}_{2}$ and oxygen saturation (in the presence of normal levels of $\mathrm{PaCO}_{2}$, bicarbonates, and base excess) indicating hypoxaemia, in 19 patients. Pulmonary function testing of 62 showed mild obstructive flow pattern in six and restrictive pattern in two. Mild to moderate leucocytosis with neutrophilia was found in 12 and 14 showed a raised erythrocyte sedimentation rate. Liver function tests showed raised SGOT (range 92-103 units/li) in 15, although serum bilirubin, total protein, albumin, and alkaline phosphatase were within laboratory reference limits as were serum concentrations of sodium, potassium, bicarbonates, urea, and creatinine.

Of 28 patients with severe precordial chest pain and dyspnoea, 10 showed electrocardiographic changes indicative of myocardial ischaemia (depressed STs or inverted $\mathrm{T}$ waves, or both, over posterior leads in seven and over anteroseptal and lateral leads in three). ECG abnormalities were associated with raised SGOT in six. Except for one 42 year old patient with a history of hypertension, all the ECG abnormalities were found in women aged 18 to 28 .

Table 2 Clinical signs

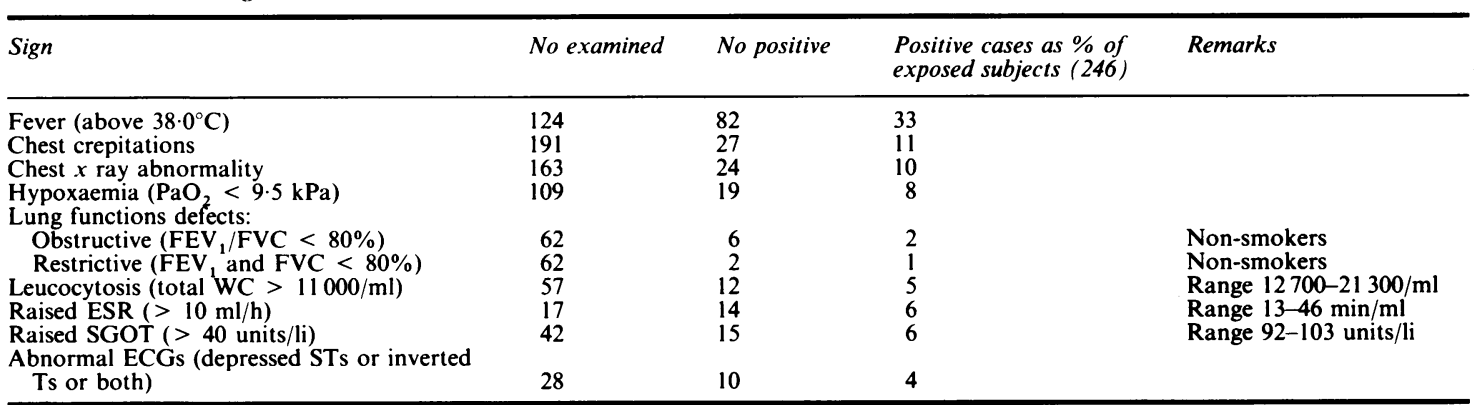




\section{Course of illness and case description}

Of the 125 patients admitted to hospital, 80 were considered fit for discharge within four days and most of the remainder after a further short observation period. Treatment was mainly symptomatic. Oxygen treatment was indicated in 11 cases, of whom the following two required intensive care.

CASE 1

The most serious case was an 18 year old girl whose working position on the sixth floor was some $5 \mathrm{~m}$ away from the first new process. She had had a cold and slight productive cough for about a week but her symptoms suddenly worsened on day 5 with shortness of breath, fever, and chills. On day 7, she was admitted to hospital in poor condition with a temperature of $40 \cdot 1^{\circ} \mathrm{C}$, tachypnoea, and signs of diminished air entry, fine crepitations, and expiratory rhonchi over both lungs.

Her blood showed raised total white cells to $26600 / \mathrm{mm}^{3}$ with neutrophilia (neutrophils $89 \%$ ). Haemoglobin and platelet counts were within the reference limits. Chest $x$ ray pictures showed extensive bilateral patchy opacities. Blood gases analysis was $\mathrm{pH} 7.49 \mathrm{kPa}, \mathrm{PaCO}_{2} 3.5 \mathrm{kPa}, \mathrm{PaO}_{2} 7.2 \mathrm{kPa}, \mathrm{HCO}_{3} 20$ $\mathrm{mmol} / \mathrm{li}$, base excess -3 and oxygen saturation $91 \%$. Bacterial cultures of sputum and tracheal aspirate showed commensals only. Repeated cultures for legionella pneumophilia were also negative.

Treated with oxygen, steroids, and antibiotics under intensive care she slowly recovered and was fit for discharge from hospital after five weeks.

\section{CASE 2}

A 22 year old woman working beside a new process on the fifth floor experienced early symptoms of throat dryness followed by cough and shortness of breath.
Her condition gradually worsened until day 9 when she was admitted to hospital with fever $39 \cdot 8^{\circ} \mathrm{C}$, signs of tachypnoea, bilateral fine crepitations. $X$ ray pictures showed mottled opacities. Blood gas analysis showed $\mathrm{pH} 7.42 \mathrm{kPa}, \mathrm{PaCO}_{2} 5.6 \mathrm{kPa}, \mathrm{PaO}_{2} 5.2 \mathrm{kPa}$, $\mathrm{HCO}_{3} 37 \mathrm{mmol} / \mathrm{li}$, base excess +2 , and $\mathrm{O}_{2}$ saturation $74 \%$.

With oxygen treatment and intensive care her recovery was rapid, and she was fit for discharge after nine days in hospital.

\section{Epidemiology}

With effects on exposed people ranging from none to serious illness, five grades of severity based on symptoms and physical signs were specified and patients were grouped to facilitate epidemiological study (table 3).

It is noteworthy that although not used as direct indices, both blood gas estimation and lung function tests corresponded well with the grading of severity. Of the 19 cases with evidence of hypoxaemia, 16 were in grade 4 and three in grade 3 . Grade 4 cases had lower mean $\mathrm{PaO}_{2}(\mathrm{p}<0.001), \mathrm{FEV}_{1} \%$ predicted $(p<0.01)$, and FVC $\%$ of predicted $(p>0.05)$ than grade 3 cases.

The figure shows the incidence of illness in relation to days of occurrence and the number of new printing processes in operation. The presentation of the oute break with early mild symptoms progressing to more serious cases appearing over a period of days accorded with the expected pattern for continuing exposure to relatively low concentrations of a toxic agent. The incidence of grade 4 cases corresponded closely with the number of machines in operation with peaking on the second day of increased exposure whereas patients in grades 1,2 , and 3 tended to peak earlier.

Table 3 Grading of severity of illness

\begin{tabular}{|c|c|c|c|c|c|c|}
\hline \multirow[t]{2}{*}{ Grade } & \multirow[t]{2}{*}{ Symptoms and signs } & \multirow{2}{*}{$\begin{array}{l}\text { 5th floor } \\
\text { No of cases }\end{array}$} & \multirow{2}{*}{$\begin{array}{l}\text { 6th floor } \\
\text { No of cases }\end{array}$} & \multirow{2}{*}{$\begin{array}{l}\text { Both floors } \\
\text { No of cases }\end{array}$} & \multicolumn{2}{|l|}{ Total } \\
\hline & & & & & No of cases & $\begin{array}{l}\% \text { of exposed } \\
\text { subjects }\end{array}$ \\
\hline $\begin{array}{l}0 \\
1\end{array}$ & $\begin{array}{l}\text { Asymptomatic } \\
\text { Eye, nose, or throat irritation and/or } \\
\text { non-specific symptoms of headache, } \\
\text { dizziness, malaise, bodyache, nausea, } \\
\text { vomiting }\end{array}$ & 14 & 4 & - & 18 & 7 \\
\hline 2 & $\begin{array}{l}\text { vomiting } \\
\text { Any or all symptoms in grade } 1 \text { and } \\
\text { cough and/or chest discomfort/substernal }\end{array}$ & 9 & 3 & - & 12 & 3 \\
\hline 3 & $\begin{array}{l}\text { pain and/or shortness of breath } \\
\text { Any or all symptoms in grade } 2 \text { and }\end{array}$ & 46 & 34 & 1 & 81 & 33 \\
\hline 4 & $\begin{array}{l}\text { fever with or without chills and/or } \\
\text { haemoptysis } \\
\text { Any or all symptoms in grade } 3 \text { and }\end{array}$ & 33 & 66 & 2 & 101 & 41 \\
\hline & $\begin{array}{l}\text { changes } \\
\text { All grades }\end{array}$ & $\begin{array}{r}6 \\
108\end{array}$ & $\begin{array}{r}28 \\
135\end{array}$ & $\overline{3}$ & $\begin{array}{r}34 \\
246\end{array}$ & $\begin{array}{r}14 \\
100\end{array}$ \\
\hline
\end{tabular}




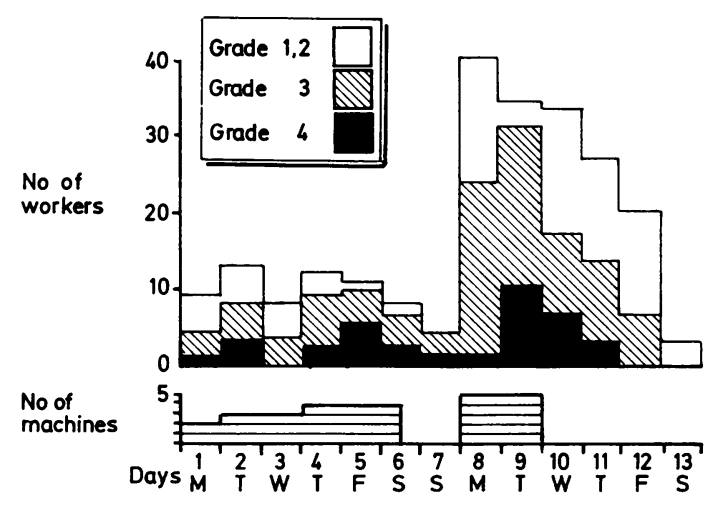

Incidence of cases and number of machines in operation.

Illness experience in relation to working distance from the new process is shown in table 4, covering 185 subjects exposed during the whole period of operation. The 34 workers who were absent for some of the time and the 27 supervisory staff and others who did not have a fixed work position were excluded from the analysis. The findings confirmed a relation between the severity of the illness and proximity to the processes.

There was also a relation between the severity and the number of processes in operation. The sixth floor with three processes had proportionately more serious cases than the fifth floor with two processes and slightly larger floor area.

There was no apparent relation between age and the severity of signs and symptoms, and because of the small number of men affected sex differences in illness were not analysed.

\section{Environmental investigation}

Hygiene investigation of the incident on the afternoon of day 10 found that the labelling operation had stopped. Battery testing for atmospheric contaminants by detector tube method was only positive for perchloroethylene at a low level of less than $5 \mathrm{ppm}$.

The new processes on the sixth floor were later tested under simulated conditions in the absence of workers. After two hours $0 \cdot 8 \mathrm{ppm}$ of ozone was recorded at the exhaust openings of the ultraviolet light enclosure and 0.5 to $0.7 \mathrm{ppm}$ of phosgene or associated acetylchlorides. Laboratory analysis of samples of ambient air from the workplace found 0.03 ppm of ozone and $0.02 \mathrm{ppm}$ of phosgene. During the test a pungent smell was noticeable after half an hour, and irritation of the eyes and throat and dry cough were experienced by some observers before the end of the period.

The test was aimed at identifying the toxic agents arising from the process and it was appreciated that the ambient air levels found would not necessarily reproduce the contamination that arose during normal work. Estimation of contamination levels from mathematical models, both static and dynamic, based on various assumptions of best and worst ventilatory conditions suggested a daily average ( 8 hour TWA) of $0.15 \mathrm{ppm}$ to $0.50 \mathrm{ppm}$ ozone on the fifth floor, $0.25 \mathrm{ppm}$ to $0.80 \mathrm{ppm}$ ozone on the sixth floor, and peak levels of $0.9 \mathrm{ppm}$ ozone on the fifth floor and $1.6 \mathrm{ppm}$ ozone on the sixth floor. Because of the varying amounts of solvent added to the cleaning pad and the possibility of more widespread production of phosgene by the interaction of ozone with perchloroethylene, phosgene levels did not lend themselves to estimation by similar methods.

\section{Discussion}

Mass gassing alarms when an unpleasant smell triggers fainting and complaints of illness are relatively common in local schools and similar hysterical manifestations among factory workers have been reported elsewhere. ${ }^{12}$ The possibility of a psychogenic reaction was considered on this occasion but the evidence for epidemic hysteria was not supported by the signs of serious physical illness or by the epidemiological analysis of the spatial and temporal distribution of the cases which suggested an exposure effect relation.

In searching for toxic agents perchloroethylene evaporating from the inking pad was the most obvious. The circumstances of use and the low air levels, however, suggested the possibility of decomposition products being more hazardous than any direct effect of the solvent.

The mercury lamp arrangement for curing the label emitted ultraviolet light at wave length $254 \mathrm{~nm}$ and

Table 4 Illness by grades and working distances from new processes

\begin{tabular}{|c|c|c|c|c|c|c|}
\hline \multirow{2}{*}{$\begin{array}{l}\text { Distance from } \\
\text { nearest machine } \\
(\mathrm{m})\end{array}$} & \multicolumn{2}{|l|}{ 5th floor } & \multicolumn{2}{|l|}{ 6th floor } & \multirow{2}{*}{$\begin{array}{l}\text { Total No } \\
\text { subjects }\end{array}$} & \multirow{2}{*}{$\begin{array}{l}\% \text { of grades } \\
3.4\end{array}$} \\
\hline & Grades 3.4 & Grades $0,1,2$ & Grades 3.4 & Grades 0.1.2 & & \\
\hline $\begin{array}{l}<4 \\
4-8 \\
>8\end{array}$ & $\begin{array}{r}14 \\
6 \\
5\end{array}$ & $\begin{array}{r}5 \\
20 \\
28\end{array}$ & $\begin{array}{l}31 \\
23 \\
21\end{array}$ & $\begin{array}{r}8 \\
12 \\
12\end{array}$ & $\begin{array}{l}58 \\
61 \\
66\end{array}$ & $\begin{array}{l}78 \\
48 \\
39\end{array}$ \\
\hline
\end{tabular}


generation of ozone by photochemical reaction with air within the curing enclosure was another possibility. It was established that ozone was produced with resulting ambient air concentrations likely to reach levels hazardous to health.

Phosgene and trichloroacetyl chlorides were possible products of the autoxidation of perchloroethylene with the reaction enhanced by ultraviolet radiation in the curing area, whereas similar products could result from reaction of ozone with the solvent in the general workplace environment. Fluctuation in production with one or other substances exceeding safe levels in ambient air was also likely. The delayed onset of grade 4 cases with pulmonary involvement some time after exposure was consistent with the known latency of phosgene poisoning but ozone exposure could produce a similar pattern.

All in all, the toxic agent responsible for the illnesses of exposed subjects appeared to be ozone, or an acid chloride either alone or in combination.

Although individual susceptibility could account for some of the differences, the wide range in the severity of the illness indicated variation in the levels of contamination to which individuals were exposed. The absence of ill effects in some, and the relatively mild complaints of eye and upper respiratory tract irritation in others, suggested that exposure in these cases was not much above the TLV of $0.1 \mathrm{ppm}$ and could correspond with the lower calculated levels of 0.15 and $0.25 \mathrm{ppm}$ of ozone. Challen and his coworkers reported respiratory tract symptoms and signs in welders after exposure to less than $2 \mathrm{ppm}^{3}$ which would correspond with estimated peak levels of 0.9 and $1.6 \mathrm{ppm}$ of ozone and the effects on some of those exposed on this occasion.

The worst cases showed pulmonary congestion and pneumonia which suggested either exposure to higher concentrations of one or more toxic gases or the exacerbation of pre-existing respiratory tract disease of bacterial or viral origin. Stockinger noted that $\overline{\bar{a}}$ ozone even in low concentrations may potentiate pre- 을 existing infection. ${ }^{4}$ Such an effect could account for $\frac{\$}{\mathbb{}}$ the early and severe illness of case 1 , who had symp- ?. toms of infection before exposure, and possibly some $\overrightarrow{\vec{F}}$ of the other cases were similarly affected.

Parkes described "substernal pain and dyspnoea suggesting myocardial infarction" as a feature of $\overline{\bar{N}}$ acute illness after exposure to ozone. ${ }^{5}$ Our obser- $\frac{\widehat{\sigma}}{\widehat{D}}$ vations indicate that myocardial ischaemia may $\varrho$ occur, and this would explain the symptoms of pain and dyspnoea. The numbers involved on this occa- $\vec{\circ}$ sion, however, did not allow determination of whether electrocardiographic changes were, in fact, a chance $\vec{\omega}$ finding or due to direct or indirect (secondary to hypoxaemia) chemical toxicity.

The help of Mr K M Gabuji, senior chemist of the $\stackrel{\stackrel{+}{N}}{\stackrel{0}{O}}$ Government Laboratory, in the analysis of the envi- $\overrightarrow{0}$ ronmental contamination in this incident and the $\dot{\circ}$ co-operation of the medical superintendent and staff $\infty$ of the Queen Elizabeth Hospital, Kowloon, are 을 gratefully acknowledged.

\section{References}

${ }^{1}$ Smith MJ, Colligan MJ, Hurrell JJ. The incidence of industrial mas psychogenic illness: a preliminary report. $J$ Occup $M$ 1978;20:399-400.

${ }^{2}$ Boxer PA, Singal M, Hartle RW. An epidemic of psychogeníc illness in an electronic plant. J Occup Med 1984;26:381-5.

${ }^{3}$ Challen PJR, Hickish DE, Bedford J. An investigation of some 을 health hazards in an inert-gas tungsten-ore welding shop. $\mathrm{Br} J$ Ind Med 1958;15:276-82.

${ }^{4}$ Stockinger HE. Factors modifying toxicity of ozone in ozone chemistry and technology. Washington: American Chemical Society, 1959.

${ }^{5}$ Parkes WR. Occupational lung diseases. 2nd ed. London: Butterworths, 1982;480. 